\title{
Online Supportive Group as social intervention to face COVID lockdown. A qualitative study on psychotherapists, psychology trainees and students, and community people
}

\author{
Emanuela Brusadelli, ${ }^{1}$ Laura Ferrari, ${ }^{2,3}$ Michele Benetti, ${ }^{2}$ Stefania Bruzzese,${ }^{2}$ Giada Maria Tonelli, ${ }^{2}$ Salvatore Gullo ${ }^{4}$ \\ ${ }^{1}$ School of Psychology, Faculty of Arts, Social Sciences \& Humanities, University of Wollongong, Australia; ${ }^{2}$ C.O.I.R.A.G., Scuola \\ Coirag Sede di Milano; ${ }^{3}$ Ariele Psicoterapia, Italy; ${ }^{4}$ Department of Psychology, University of Palermo, Italy
}

\begin{abstract}
Several psychological interventions have been activated to help people during the coronavirus pandemic, and research highlights the crucial role of group interventions as a space for sharing and processing the psychological experiences linked to this emergency and the consequent changes in people's lifestyles. In this context, psychologists are mostly providers of this kind of service more than users. This study aimed at investigating and comparing post-hoc the subjective experience of psychotherapists, psychology trainees \& students, and individuals of the general population who participated in a psychodynamically-oriented supportive group intervention. Fifty-two subjects were enrolled to participate to focus groups aimed at exploring participants' decision to participate, their perceptions on how the support group influenced their elaboration of the psychological effects of pandemic/lockdown, and their feedback on its utility. Transcripts of the focus groups were analyzed with the Linguistic Inquiry Word Count (LIWC). Differences in the use of words/linguistic categories between groups were tested through chi-square tests. Content analysis was conducted by independent judges who extracted the most relevant comments. Preliminary results showed the main features related to the crisis response, and how belonging to different social roles was associated with different ways of experiencing and sharing emotions. People react in different ways to traumatic events, and how people react may say a lot about how they cope with the event and the extent to which the event plays a role in the future. Clinical implications on the use of this data for future treatment planning are also discussed.
\end{abstract}

Key words: COVID-19 lockdown; online psychological group intervention; focus groups; Linguistic Inquiry and Word Count (LIWC); psychodynamic approach.

Correspondence: Emanuela Brusadelli, School of Psychology, Faculty of Arts, Social Sciences \& Humanities, University of Wollongong, NSW 2522 Australia.

E-mail: emanuela@uow.edu.au

Citation: Brusadelli, E., Ferrari, L., Benetti, M., Bruzzese, S., Tonelli, G. M., \& Gullo, S. (2020). Online Supportive Group as social intervention to face COVID lockdown. A qualitative study on psychotherapists, psychology trainees and students, and community people. Research in Psychotherapy: Psychopathology, Process and Outcome, 23(3), 279-290. doi: 10.4081/ripppo.2020.501

Acknowledgments: We thank S. Banzatti, F. Benvenuto, F. Berra, M.T. Grilletta, M. Guerrini, S. Morgante, E. Patriarca, and S. Soldatesca for their contribution for the focus groups.

Received for publication: 28 September 2020.

Revision received: 1 December 2020.

Accepted for publication: 1 December 2020.

This work is licensed under a Creative Commons Attribution NonCommercial 4.0 License (CC BY-NC 4.0).

${ }^{\circ}$ Copyright: the Author(s), 2020

Licensee PAGEPress, Italy

Research in Psychotherapy:

Psychopathology, Process and Outcome 2020; 23:279-290

doi:10.4081/ripppo.2020.501

\section{Introduction}

Coronavirus disease 2019 (COVID-19) pandemic is an emergency event that has been deeply influencing people's daily lives and mental health, and that we can conceive as a traumatic event. Indeed, according to Foa's emotional processing theory (Foa \& Rothbaum, 1998; Foa, Steketee, \& Rothbaum, 1989), traumatic events violate the basic concepts of safety that people hold, with associated intense emotions. Hence, the substantial psychological impact of the outbreak and its consequent response is related to an increase in psychological problems, including anxiety, depression, and stress (Duan \& Zhu, 2020; Lima et al., 2020).

Additionally, measures to limit viral transmission generate prolonged periods of isolation and loneliness, with an impact on social interactions.

Indeed, the pandemic has attacked not just individuals but also their relationships and the groups related to those relationships that deeply influence their existences (Marmarosh, Forsyth, Strauss, \& Burlingame, 2020). For these reasons, Marmarosh and colleagues (2020) highlighted how extremely important groups can be when preventing and treating people who are suffering during COVID-19.

Research amply demonstrates the overall efficacy of 
group psychotherapy and its high cost-effectiveness (Burlingame \& Krogel, 2005). In this scenario, the psychoanalytic and psychodynamic group approaches emerged as valuable since therapists with this orientation could recognize early the potentiality of the group for these situations and could use an adequate technique tailored to the particularity that the psychological work in the group required. The efficacy and effectiveness of the face-to-face psychodynamic group intervention have been established and supported by findings from primary studies and earlier meta-analyses in recent years. Psychodynamic groups showed effect for different clinical populations such as general psychiatric and trauma-specific symptoms, (Lau \& Kristensen, 2007), anxiety disorders (Barkowsky et al., 2016), personality disorders (Lorentzen et al., 2015), and in different settings (Blackmore et al., 2009; Jensen, Mortesensen \& Lotz, 2010). Evidence collected showed also that the psychodynamic group outcome was equivalent to that achieved through individual psychotherapy (Burlingame \& Jensen, 2015).

During this season of crisis, the online/virtual modality has been adopted and designed to provide support (Wallace, Wladkowski, Gibson, \& White, 2020). Although the online space made it necessary to modify and adjust some aspects of the group process, virtual groups represent an affordable and convenient way to protect mental health during a time of social distancing (Marmarosh et al., 2020). Groups provided a non-judgemental space in which people may share concerns and hopes, and gain support and insight from others. In literature, there is a lack of research on the efficacy/effectiveness of online group therapy, and, as far as we know, there is only one trial of Internet-based substance abuse therapy utilized videoconferencing to conduct twice-weekly online group therapy sessions (King, Brooner, Peirce, Kolodner, \& Kidorf, 2009).

Current research regarding online support groups focused on the importance of this intervention for people who suffering from physical and debilitating illnesses. Positive outcomes have been collected regarding, for example, the internet-based group support to cancer depressive patients (Gustafson et al., 2001; Winzelberg et al., 2003). According to Rodgers \& Chen (2005), participation in these groups elicited positive coping toward breast cancer and improved mood. Regarding this, a lot of attention has been paid to the effects of online support groups, especially for cooperative self-organization, mutual helping methods, and social support interventions (Segal, Silverman, \& Temkin, 1993).

The psychodynamic processes are important for understanding and managing individual and group problems and behaviors associated with pandemics such as the denial and others defensive reactions, spreading panic, stigmatization, under-reactions, and over-reactions, socially disruptive behavior, hoarding. In some cases, for example, people explicitly refusing to acknowledge the threatening reality even when presented with indisputable data, while others intentionally engaging distractions to eliminate from consciousness any thoughts of the threatening reality. The aim of the present study was to qualitatively explore the participation of individuals in a supportive psychodynamically oriented group designed to help people to face the first lockdown in Milan (Italy) in March 2020.

In that period, the need for psychological interventions was urgent but the pandemic created an excess load on the Italian healthcare system, which had already been characterized by a low number of mental health professionals in public services as a result of a general lack of community programs and investments addressing these aspects (Carta, 2019). For these reasons, some private psychological supporting options were activated to allow people to find the nearest psychologist/psychotherapist and book a free teleconsultation (Marazziti, Pozza, Di Giuseppe, \& Conversano, 2020). A considerable portion of these supportive groups had been developed only for specific targets that have been recognized as high-risk groups: online groups raised for health careers, COVID19 patients, relatives of COVID-19 victims, elderly people or teenagers, groups to support mothers of infants, young children, etc. (Weinberg, 2020).

In this context, psychotherapists seemed to receive attention especially for their role as care providers.

Indeed, studies on psychotherapists and COVID-19 investigated their relation with the online setting (e.g., Békés \& Aafjes-van Doorn, 2020; Boldrini, Lomoriello, Del Corno, Lingiardi, \& Salcuni, 2020; Farber, Ort, \& Mayopoulos, 2020; Humer, Stippl, et al., 2020; MacMullin, Jerry, \& Cook, 2020; McBeath, du Plock, \& Bager Charleson, 2020; Poletti et al., 2020), their fear of becoming infected with COVID-19 during psychotherapy in personal contact with relapses on their clinical activity (Humer, Pieh, et al., 2020; Probst, Tagini et al., 2020), their role as informants on their patients' wellbeing (Probst, Humer, et al., 2020b).

Only a few studies focused on their wellbeing. Probst and colleagues (Probst, Kuska, et al., 2020) conducted a survey that showed high levels of stress and job-related worries for psychotherapists, especially for the ones who had no other sources of income besides psychotherapy. Aafjes-van Doorn, Békés, Prout, \& Hoffman (2020) evaluated the presence of a higher level of vicarious trauma in association with variables like younger age, less clinical experience, and negative online treatment experience. Finally, one study (Kent, Hogan, Riddle, \& Heesacker, 2020) investigated the experience of psychotherapist-intraining testing positive for COVID-19.

All authors supported the need for personal and professional support for psychotherapists, especially during this global health crisis. To the best of our knowledge, no studies focus on interventions on psychotherapists as users of a supportive service.

The goals of this study were to investigate the participation of these categories of professionals in a psycho- 
dynamically-oriented supportive intervention, and their similarities and differences with the general population. The target of the intervention provided were psychotherapists, trainees in psychology and psychology students, and individuals of the general population (named соттиnity). Specifically, we were interested in their decision to participate in this program, how the group experience influenced how their way to elaborate the psychological effects of pandemic and lockdown, and their perception of the utility of this intervention.

To pursue these objectives, we adopted a qualitative approach, conducting a focus group with each group of participants two weeks after the intervention. Data were analyzed with the Linguistic Inquiry Word Count (LIWC; Pennebaker et al., 2015; Pennebaker, Francis, \& Booth, 2007), a computer text analysis program which is considered one of the most valid tools to provide an efficient and effective method for studying the various emotional, $\operatorname{cog}$ nitive, and structural components present in verbal and written speech samples (Pennebaker, Boyd, Jordan, \& Blackburn, 2015; Tausczik \& Pennebaker, 2010).

During the COVID pandemic, the LIWC was used in different contexts, especially to analyze data coming from social media platforms, with some discrepant outcomes.

$\mathrm{Su}$ and colleagues (2020) examined the impact of COVID-19 Lockdown in Lombardy and Wuhan analyzing psychosocial expressions on social media users, comparing people's psychological status before and after the beginning of the lockdown in the two areas. Surprisingly, data of Lombardy indicated a significant decrease in the frequency of affective process words, specifically anxiety, after the beginning of the lockdown, together with an increase of cognitive mechanism words (e.g., discrepancy, possibility) and personal concern words (e.g., home, leisure). These results were not in line with quantitative surveys conducted in Italy which confirmed the relatively high rates of posttraumatic stress symptoms, depression, anxiety, insomnia, perceived stress, and adjustment disorder symptoms (Casagrande, Favieri, Tambelli, \& Forte, 2020; Mazza et al., 2020; Moccia et al., 2020; Rossi et al., 2020).

Abdo, Alghonaim, and Essam (2020) investigated with the LIWC the public perception of COVID-19's global health crisis on Twitter until 14 weeks after the outbreak, showing high levels of anger, anxiety, doubtfulness, and of contents related to cognitive processes.

Similarly, Herat (2020) analyzed material from different internet sources of Britain and Sri Lanka to evaluate the psychological effects of the lockdown. They found more negative emotions in the stories than positive emotions, together with high overall use of cognitive words and personal pronouns. They also registered a high use of the first person singular pronoun that was used five times more than the first person plural pronoun.

Li, Wang, Xue, Zhao, \& Zhu (2020) examined Weibo users' data and found how people showed more negative emotions (anxiety, depression, and indignation) and less positive emotions after the declaration of COVID-19 on the $20^{\text {th }}$ of January.

The study by Essan \& Abdo (2020) on Arab Tweeters on a 12-week interval indicated stability on the levels of analytical thinking, with anxiety and hostility that were replaced by more ambivalent feelings at the end of March. They also showed high scores of insight-words that indicate high levels of individualism and rationality.

Interestingly, these results are in line with a study by Barrett (2020) who used the LIWC to explore dreams during the pandemic. The author showed how, during the pandemic, in March, there were higher contents related to health, death, negative emotions and anxiety, and lower levels of positive emotions for both female and male compared to normative data.

To the best of our knowledge, none of those studies address psychotherapists as users.

This study aimed at exploring the subjective experience of psychotherapists, psychology students \& trainees, and individuals of the general population during the COVID pandemic after they participated in an online psychodynamically-oriented group intervention. We investigated 1) similarities and differences in the perception of COVID-19 reality and in their way they answered to the stimuli provided during a focus group 2) the proportions of linguistic categories associated with pronouns, emotions, and cognitive processes in these different groups.

Specifically, based on the existing studies, it was hypothesized for all the groups of participants lower scores on the LIWC scale of positive emotions, and higher scores of negative emotions, anxiety, anger, sadness, together with higher contents linked to cognitive processes. Regarding psychotherapists, from a clinical perspective, we hypothesized higher insight and attention to inner feelings and more emotional contents than younger colleagues and individuals of the community.

\section{Materials and Methods}

\section{Participants}

In March 2020, the School of Specialization in Psychoanalytic Psychotherapy COIRAG in Milan was one of the first centers that provided an online group intervention called "COndiVIDi" (the Italian word for sharing) to support people facing the distressing condition of the lockdown. The target of the intervention were psychotherapists, psychologists in training, clinical psychology students, and the general population.

The school offered for free a psychodynamically-oriented three-weekly group sessions based on Yalom's Curative Factors (Yalom \& Leszcz, 2005) and carried out by two expert psychotherapists.

A total of 131 participants were recruited on social networks and through snowball recruitment, and divided into groups composed of from 8 to 12 participants. 
One week after the end of the intervention, they were all invited via email to voluntarily participate in a onesession focus group to share feedback on the experience. The invitation was accepted by 52 individuals, who were grouped into three categories: psychotherapists ( 2 focus groups, $\mathrm{n}=25,45$ male; $\mathrm{M}$ age $=44.24 \pm 11.90 ; 24 \%$ married, $48 \%$ unmarried, $4 \%$ divorced, $4 \%$ widowed, $8 \%$ de facto, $12 \% \mathrm{n} / \mathrm{a}$ ), psychology trainees and students ( 2 focus groups, $\mathrm{n}=14,4$ male; $\mathrm{M}$ age $=25.95 \pm 2.39 ; 7.14 \%$ married, $92.86 \%$ unmarried), individuals of the general population ( 2 focus groups, $n=13,1$ male; $M$ age $=42.78 \pm 17.02$; $15.38 \%$ married, $53.85 \%$ unmarried, $7.69 \%$ divorced, $23.08 \% \mathrm{n} / \mathrm{a})$.

\section{Procedure}

The one-session focus groups lasted 90 minutes and were videotaped. The present research project was approved by the Ethics Committee of the COIRAG and all subjects involved signed the consent form, which included the acceptance of being recorded and of the use of the material for research purposes.

Specifically, the focus group was designed to explore their decision to participate in the supportive program, how the group experience influenced their elaboration of the psychological effects of pandemic and lockdown, and their perception of the utility of the intervention. Each focus group followed the standard procedure (Krueger, 2014) and were facilitated by one experienced psychotherapist (4 in total, 1 male, $\mathrm{M}$ age $=40.00 \pm 7.31$ ) who was not directly involved in the previous group interventions, together with one psychologist in training as a co-conductor (3 in total, all females, $\mathrm{M}$ age $=25.33 \pm 1.15$ ), who was also the person who transcribed the recorded material.

At the beginning of each focus group, the purpose of the meeting was discussed, together with the declaration of the use of the material for research aims. Participants were asked to introduce themselves, then conductors facilitated the participants' free expression in a confidential, respectful, and non-judgmental climate. They guided the group discussion through three main areas: their needs and expectations on the group intervention, and if their point of view/perception on the COVID emergency and their professions changed after this experience (Needs and expectations toward the supportive group); which aspects they understood of themselves and of their reactions toward the COVID emergency, including their way of feel/recognize emotions and their view/understanding of other people (Elaboration of pandemic experience); which aspects of the group intervention they found more useful, what they would have been changed of it, and which aspects helped or impeded their participation and sharing into the groups (Utility of the group intervention). The topics of these areas were established a priori but not the time for each one. The only instruction that was given to conductors was to cover all the areas in the 90 minutes but to leave participants free to contribute for each one following their preferences. Tran- scripts obtained from the focus groups were then analyzed through the Linguistic Inquiry Word Count, version 2015 (LIWC 2015; Pennebaker et al., 2015; Pennebaker, Francis, \& Booth, 2007), a psycholinguistic tool that analyzes the linguistic features of the targets' written self-descriptions. The reliability and validity of LIWC analyses have been well-established in many contexts (cf. Pennebaker et al., 2015). The linguistic features were extracted from transcripts by using the Italian LIWC dictionary (Agosti \& Rellini, 2007). Through this analysis, we obtained frequency distributions of specific words and the different topics of the focus groups.

In this study, we assessed the elected psycholinguistic features: pronouns (I, We); affective process words (positive and negative emotions); cognitive mechanism words (causation, discrepancies, introspection, possibilities).

Additionally, following this first step, a content analysis had been conducted. Based on LIWC results, two couples of independent judges (MB\&SB LF\&GT) read the transcripts and extracted the most relevant comments, together with an interpretation of this material. They were 3 females and 1 male, all trained psychotherapists with extensive knowledge of clinical contents. Each of them did this activity separately, then they discussed together in couple to find an agreement around which parts to select and which interpretations to formulate.

\section{Statistical analysis}

Statistical analyses were conducted on data extracted as follows: first words were dichotomous (yes/no) according to whether they belonged to "Need", "Elaboration", or "Utility", then words belonging and not belonging to any specific category were counted for each type of the three groups (trainees and student, psychotherapist or community). Data were not organized per-subjects but aggregated for each focus group, therefore we had not distribution but just frequency. The same procedure was followed for the words of all the other linguistic categories extracted from LIWC ("I" and "We" pronouns, affective and cognitive categories). In order to compare a specific focus group with the others, word and category distributions were calculated by grouping the frequencies of all focus groups minus the specific focus group considered. Relationships between two variables (e.g. linguistic category and type of focus group) were assessed by $2 \times 2$ contingency tables performing the chi-squared test, a significance level of $\mathrm{P}<0.05$ was adopted.

\section{Results}

Table 1 shows the distribution of words that each group spent in discussing the three themes established a priori: Needs and expectations toward the supportive group, Elaboration of pandemic experience, and Utility of group intervention. Qualitative results were reported 
maintaining the same grouping order: psychotherapists, trainees and students, community.

\section{Needs and expectations toward the supportive group}

The first topic "Needs and expectations toward the supportive group" was the main discussed argument during the focus groups ( $42 \%$ of the total words).

The psychotherapists spent almost one word out of two of those detected by LIWC to talk about this topic $(48 \%)$, more than the other groups $\operatorname{did}\left(\chi^{2}=145.43, \mathrm{P}<0.01\right)$. The analysis of the contents seems to indicate that psychotherapists were searching for support from other colleagues both as a person and as a professional, to quit from the isolation they perceived and find a container for thoughts and emotions. An excerpt from the transcripts of this group illustrates the meaning of this point:

"[...] find colleagues who would help me to reconstruct a therapeutic thought ... find high thoughts as to say, (my usual) therapeutic thoughts .. the need that I felt strong at that moment was to have a container, I felt a bit the lack of a container where I could try to put thoughts not only of a professional but also a personal kind - to be able to compare with colleagues both professionally and on a human level ... the need behind it was to get out of isolation ...".

Interestingly, many clinicians stated that their expectations on group intervention were to share ideas on how to conduct online therapies and that the COVID emergency changed their perception of technological tools.

"I started from the expectation that we would talk a little more about how to do online therapy - It is as if the emergency had forced me to deal with work situations that I would have never had before ... I would have never started making video calls or videoconferences ... the really surprising thing for me was that my way of thinking about online groups has changed".

In the community group, emerged a strong need and desire to socialize and to feel connected with other people, while trainee\&student group discussed less (37\%) than the other groups this topic ( $44 \%$ on average), showing fewer expectations towards the possibility of receiving support from this group.

\section{Elaboration of pandemic experience}

The topic "Elaboration of pandemic experience" was more present in the community group (45\%) than in groups composed of psychotherapists (34\%), or trainees\&students (33\%). The analysis of the content seems to show that psychotherapists focused more on the understanding of their strategies to contain and manage emotions, and how these influence their life from different perspectives. They underlined how the power of their emotions limits their abilities to reflect, and how they need more time to think about what is happening to them, asking for an extra-space (more group sessions) to face together feelings of detachment, the anguish of distance, and isolation.

"at this moment we are not free to be able to choose thoughts, to be able to choose actions and therefore also understand what was positive and negative, [..] it is very difficult now to give an opinion [... I really have to make an effort to go back with my mind to a month ago".

Participants of the community group, on the contrary, underlined the importance of sharing the situation and their strong emotions with other people, perceiving the COVID as a universal condition:

"(the group) made me feel that I was looking at this COVID in a way of sharing, not being alone [..], of sharing, of feeling-it allowed me to know contexts [..] this universality helped me to know and understand the context in which I live."

Trainees\&students highlighted the importance of processing one's emotions, and how in the group this is possible through sharing and comparison with others. This led to the recognition of their avoidant strategies to face emotions:

"from both my personal experience and what I saw recurring in the group, it was the maneuver of avoiding unpleasant emotions (..) for me it became

Table 1. Distribution of themes among focus groups.

\begin{tabular}{lcccc}
\hline Topic areas & Overall & $\begin{array}{c}\text { Students and Trainees } \\
\text { (a) }\end{array}$ & $\begin{array}{c}\text { Psychotherapists } \\
\text { (b) }\end{array}$ & $\begin{array}{c}\text { Community } \\
\text { (c) }\end{array}$ \\
\hline Needs and expectations toward the supportive group & $42 \%$ & $37 \%^{\mathrm{a}, \mathrm{c}}$ & $48 \%^{\mathrm{a}, \mathrm{b}, \mathrm{d}}$ & \\
\hline Elaboration of pandemic experience & $37 \%$ & $33 \%^{\mathrm{c}, \mathrm{d}}$ & $34 \%^{\mathrm{b}, \mathrm{d}}$ & \\
\hline Utility of group intervention & $21 \%$ & $3 \%^{\mathrm{a}} \%^{\mathrm{a}, \mathrm{b}, \mathrm{c}}$ & $45 \% \%^{\mathrm{a}, \mathrm{b}, \mathrm{c}}$ \\
\hline
\end{tabular}

Superscripts $\mathrm{a}, \mathrm{b}, \mathrm{c}$ and ${ }^{\mathrm{d}}$ indicate which groups are significantly different. 
a space for processing the emotions of all the emotional movements that were overwhelming me and for which I struggled alone (..) I saw a lot of emotion in sharing and it helped me to be a little more in the emotions, my perception has changed".

and of the difficulty of dealing with one's limits, even on a professional level:

"the topic of being a psychologist emerged a bit. Rethinking precisely the role (..) that is, we cannot save the world (..) starting from the confrontation with the group I realized that initially we dissociate a lot to compartmentalize things and stay inside them, afterward a strong sense of tenderness emerged (..) I felt in the group this difficulty in staying in the annoying dimension of the limit [..] I was not aware of the emotions I was feeling - it was a way to access other emotional aspects that usually do not face each other".

\section{The utility of group intervention}

The greatest number of words regarding the theme of "Utility of group intervention" was found in the trainee\&student group (30\%), which talks about it more than psychotherapist (18\%) and community group (13\%). All groups agreed on the importance of sharing emotions and the interpersonal learning coming from listening, but each of them had a different perspective on which elements were more helpful for them and their self-disclosure.

Psychotherapists reflected on the online groups as a tool, both as consumers and as professionals. Starting from their personal experience, they overcame their resistance around the use of technology for therapeutic purposes, finding the group an effective tool.

Regarding their self-disclosure, they highlighted how sharing groups with other colleagues was the most helpful factor for this purpose.

"What certainly facilitated me a lot was the type of listening that was in the groups, that is, in the group over time both by the conductors and by the people who participated and I thought it would not be so easy for me in a group of non-psy colleagues... I made this a little... this fantasy".

For the community participants, the group was useful to learn the importance of the here-and-now to tolerate the uncertainty of the situation, together with the universality of their condition. Some of them explicit the desire to have more sessions:

"Let's say that the group allowed me to... understand the importance of the present, to obviously focus on the current situation, taking one step at a time, without making too many projections"
Trainees and students underlined how the group represented a secure setting where they can feel and express their intense emotions or as an anchor point in a situation that was like a "limbo" and stressed the importance of the group to face their isolation:

"The way in which I have changed the way I perceive my emotions may be connected to, I don't know, a greater acceptance perhaps of emotional states that I usually did not allow myself, did not allow myself to feel" [...] "the group helped me in a complicated, difficult, new moment, to make more contact, sharing it with other people, hearing parts played by others during the group".

Interestingly, they also highlighted the importance of a clear and defined setting: the presence of a marked timeframe for both the sessions and the whole intervention was reassuring compared to the external/undefined situation they were living in. They state that this facilitated their self-disclosure.

"I was struggling a bit at the end. But we reasoned precisely on the fact that it was really nice to know that this thing was finishing, that we knew there was a limit, a container, compared to the situation outside COVID, which instead we don't know when it will end and it is an indefinite situation. This was very reassuring".

\section{Exploration of the linguistic categories associated with pronouns, emotions, and cognitive processes in the three groups}

As shown in Table 2, also the frequencies of the categories of words indicate some differences among the four groups.

\section{Singular and plural pronouns}

Overall, groups tended to use more frequently singular than plural pronouns ( $14 \%$ vs $4 \%$ ),

psychotherapists more than participants in other groups $\left(16 \%\right.$ vs $13 \%$ on average; $\left.\chi^{2}=11.92, \mathrm{P}<0.01\right)$. The analysis of the content seems to indicate that psychotherapists use more this pronoun as a result of their focus on their own experiences. Indeed, they seem to search for belonging and for a place where they can talk the same language with professionals like them, but at the same time they are reluctant and with prejudices, especially when differences emerge related for example to age, origin, etc., and were surprised to find the other people (and sharing with them) interesting.

"the level of communication, of exchange, in my opinion, was very horizontal as if the institutional 
hierarchies had jumped... I thought that another therapist younger than me had nothing to say to me then I saw how different origins still manage to talk to each other".

On the contrary, the use of "we" was more evident (although very small, $4 \%$ ) in the group of the community people, as a way for the group members to express their need for belonging and of facing their isolation with a strong sense of intimacy.

"now we belong - as regards what happened in our group - it was an experience of humanity and depth - I see myself in a more expanded community reasoning [..] I saw how the group was let's all say in the same boat - we talked quietly about ourselves - we helped each other in the interpretation of what was happening [..] is it was more a focus on ourselves [..] the disease and the outside we have not talked about it much".

Regarding trainees and students, the analyses of the content seems to indicate a shift during the focus group, with higher use of "I" ("io" in Italian) at the beginning to introduce and distinguish themselves, and take the floor. Progressively, it was more frequent the use of me too (anche io, in Italian), supporting the sharing of situations and emotions among participants, and how they were mirroring each other. The pronoun "we" was also more common in the last part of the session (4\%), demonstrating a higher definition and involvement as a group.

\section{Affective process}

The use of affective process words was similar in all the groups, ranging from $13 \%$ (in the psychotherapist group) to $17 \%$ (in the community group) (see Table 2). Going deep into the examination, the percentages of positive emotion for all groups was 1-2\%, whereas the use of negative emotions was significantly higher ranging from $5-6 \%\left(\chi^{2}=795.14, \mathrm{P}<0.01\right)$. The analysis of the content seems to show for all groups, although in a different amount, a general tendency to avoid emotions as a strategy to face the difficult reality and how the group intervention made them more aware of this mechanism.

Psychotherapists underlined the presence of defenses

Table 2. Distribution of categories among focus groups.

\begin{tabular}{|c|c|c|c|c|c|}
\hline & Overall & Students and Trainees & Psychotherapists & Community & Comparison to average of other groups \\
\hline & $\%$ & $\%$ & $\%$ & $\%$ & \\
\hline Pronoun "I" & 14 & 16 & 18 & 15 & $\begin{array}{l}\text { Psychotherapists, } \chi^{2}=117.56, \mathrm{P}<0.001 \\
\text { Students and Trainees, } \chi^{2}=15.66 \mathrm{P}<0.001 \\
\text { Community, ns }\end{array}$ \\
\hline Pronoun "we" & 4 & 3 & 2 & 5 & $\begin{array}{l}\text { Psychotherapists, } \chi^{2}=88.31, \mathrm{P}<0.001 \\
\text { Students and Trainees, ns } \\
\text { Community, } \chi^{2}=88.23, \mathrm{P}<0.001\end{array}$ \\
\hline Affective process & 15 & 15 & 13 & 17 & $\begin{array}{l}\text { Psychotherapists, } \chi^{2}=11.91, \mathrm{P}<0.001 \\
\text { Students and Trainees, } \chi^{2}=20.03, \mathrm{P}<0.001 \\
\text { Community, } \chi^{2}=103.45, \mathrm{P}<0.001\end{array}$ \\
\hline Positive emotions & 2 & 2 & 1 & 2 & $\begin{array}{l}\text { Psychotherapists, ns } \\
\text { Students and Trainees, } \chi^{2}=4.61, \mathrm{P}=0.031 \\
\text { Community, ns }\end{array}$ \\
\hline Negative emotions & 5 & 5 & 5 & 6 & $\begin{array}{l}\text { Psychotherapists, } \mathrm{ns} \\
\text { Students and Trainees, } \mathrm{ns} \\
\text { Community, } \chi^{2}=40.58, \mathrm{P}<0.001\end{array}$ \\
\hline Causation & 8 & 9 & 9 & 9 & $\begin{array}{l}\text { Psychotherapists, ns } \\
\text { Students and Trainees, } \chi^{2}=4.84, \mathrm{P}=0.027 \\
\text { Community, ns }\end{array}$ \\
\hline Introspection & 10 & 12 & 10 & 10 & $\begin{array}{l}\text { Psychotherapists, } \mathrm{ns} \\
\text { Students and Trainees, } \chi^{2}=53.07, \mathrm{P}<0.001 \\
\text { Community, ns }\end{array}$ \\
\hline Discrepancies & 7 & 7 & 10 & 10 & $\begin{array}{l}\text { Psychotherapists, } \chi^{2}=96.39, \mathrm{P}<0.001 \\
\text { Students and Trainees, } \chi^{2}=29.62, \mathrm{P}<0.001 \\
\text { Community, } \chi^{2}=102.54, \mathrm{P}<0.001\end{array}$ \\
\hline Possibility & 16 & 14 & 19 & 19 & $\begin{array}{l}\text { Psychotherapists, } \chi^{2}=204.51, \mathrm{P}<0.001 \\
\text { Students and Trainees, } \chi^{2}=4.55, \mathrm{P}=0.032 \\
\text { Community, } \chi^{2}=172.13, \mathrm{P}<0.001\end{array}$ \\
\hline
\end{tabular}

\#Average of other groups is obtained by subtracting the percentage of words used by the group considered from the overall average. 
around emotions, with feelings of fears and a sense of inadequacy, and a need for a security device for emotions.

\begin{abstract}
"at this moment the safety device of emotions and experiences is to put together what you are feeling (..) on the one hand there was this confirmation that we are not enough and the certainty that we are no longer the same, now we go away with less fear and more courage - sharing allowed me to become more aware of the defenses I was activated [...] and then our group acted as a container, it was possible to hear more things and it was great nourishment."
\end{abstract}

In the community group, participants underlined more a state of confusion, a problem in understanding their emotional world, perceiving themselves as "stuck" and/or "in the quicksand", and how this was associate with feelings of guilt. For this reason, they stressed the importance of the group as a place to share and accept these feelings, and to discover that also other people share the same problems, with an optimistic view of the future.

"the group taught me to forgive .. to forgive myself because in this situation I was not as efficient as I was and I felt guilty [..] seeing that other people also had difficulty managing their day, their thoughts [. .] made me feel a little less alone in this".

Analysis on the trainees and students confirmed the positive impact of the group and how it helped them to discover an unknown sense of proximity with other people, which helped them to get more in touch with their real emotions:

"at the beginning of the group maybe before I wasn't in contact with real emotions (..) what helped me to do the group is feeling more closeness with others- [..] it was a way to access other emotional states that we don't usually deal with - it was interesting to see myself in anguish."

Similarly, they also highlighted the possibility in the group to recognize and tolerate the intensity of their emotional world:

"avoid particular emotions but rather go in search of answers to questions we were asking ourselves".

\section{Cognitive mechanisms}

Viceversa, the use of cognitive process ranged from $44 \%$ (trainees and students) to $49 \%$ (in the community sample), showing on an average higher percentage of use for this category than the affective one (47\% vs 20\%; $\chi^{2}=1121, \mathrm{P}<0.01$ ). The categories Possibility (words like "maybe") and Discrepancy (e.g., "if") were more used in the community group and the psychotherapist's group
(19\% and $10 \%$, respectively) than in the trainees\&student's group (11\%). The analysis of the content seems to show that the community group used the group intervention to feel more active, instead of passive, in this condition, and to feel the possibility to make some changes and to keep them in the future. Indeed, they notice differences, underline the power of sharing emotions, perceive a "forever" modification in "their way of communicating", and feel the possibility to use different participants' opinions as a source of growth accepting the presence of different experiences and points of views.

"Since the sea in this period is particularly stormy... the drops risk of being perceived a little less, but for this reason I have to say, they are not less valuable here ... therefore, even being able to simply grasp an aspect of difference or of utility ... compared to before ... The only thought that there was also this project... the fact that someone thought about putting people together so that they could share this topic has already been a useful thing".

In the psychotherapist's group, these cognitive words seem to more related to how they talk about their prejudice toward the group intervention and how their idea on it changed, on their difficulty to freely show themselves and to leave their professional role, using variables as age and clinical experience as shelters.

"maybe the difference of age a little benefited me..., facing a situation so objectively and subjectively demanding, traumatic, unexpected, terrible ...perhaps requires a certain Self-structure”.

Additionally, contrary to our hypothesis, words related to introspection were used more by trainees\&students than psychotherapists (and the community group) $\left(\chi^{2}=\right.$ 53.07, $\mathrm{P}<0.001$ ).

The content analysis seems to indicate a cognitive elaboration of their emotional processes, with a beneficial internalization of the group experience

"I heard... in me... to resound and to provide of a meaning ... the emotion I felt during the group and that I felt even later the conclusion of the group. And... and it has been very helpful to me, in the sense that... although absolutely strangers at the beginning, I was able to share, to find also a resonance, let's say, and recognition more or less of the same emotion".

\section{Discussion}

The goal of the present study was to qualitatively explore the psychological effects of pandemic and lockdown by analyzing the experiences of psychotherapists, psy- 
chology trainees and students, and individuals of the general population after they participated in an online supportive group. The focus group was considered as the elective instrument because of its capacity to share feelings, thoughts, and support reflection among participants. Although the preliminary nature of the empirical results we found must be kept in mind, across the groups our findings confirmed the presence of a condition of isolation, suffering, and uncertainty as highlighted by all participants. These data are in line with findings from quantitative research on the phenomenon both in Italy (e.g., Casagrande et al., 2020; Mazza et al., 2020; Moccia et al., 2020; Rossi et al., 2020) and in other Countries (e.g., Duan \& Zhu, 2020; Lima et al., 2020). They seem also to be supported by the analysis of the content of the linguistic categories, which showed high use of the first person singular pronoun and low use of the first plural pronoun in all the three groups, especially in psychotherapists, together with higher words related to cognitive processes. According to the literature (Herat, 2020; Pennebaker \& Niederhoffer, 2003), indeed, a high number of first-person singular pronouns and cognitive processes could be related to mental distress.

Regarding the experience of the online group intervention, most participants showed a great expectation of being part of a group and perceived it as a helpful tool to overcome difficulties, receive support, make sense of the chaos they were experiencing. Sharing emotions and learning from other people's experiences and points of view were the most important aspects underlined, together with the importance of the universality of their condition that helped them to face their emotions. Our results regarding the presence and the management of emotions in the group are controversial. On one side, qualitative data indicate the group helped participants to be more aware of the intensity of their emotional worlds, of the difficulty in understanding what they feel (especially by the community group), and of their avoidant strategies to tolerate them. On the other side, we found low percentages of words related to positive and negative emotions in all groups. Regarding this, it should be remembered that the small number of participants and groups involved in the study is a relevant limitation and represents a potential bias for all the study findings. However, data are in line with the findings found by Su et al. (2020) in Lombardy. People mentioned the presence of anguish, guilt, fear, and inadequacy, but in their discussion seemed to be present the tendency to avoid or minimize feelings related to threats and consequences (Floyd, Prentice-Dunn, \& Rogers, 2000). Similarly, the high use of cognitive process words for all the four groups may confirm this avoidance from emotions and indicate the need to find explanations and rationalize what has been happening (reappraisal). According to C. Hill (1987), our results seem to suggest that in-group coping mechanisms can be framed in an attempt to acquire reassuring information from others.
Examining how the same topics were treated differently within the three categories, data seem to indicate significant peculiarities.

Comparing psychotherapists, trainees and students, and community, data show that psychotherapists focused more on talking about their needs and expectations toward the supportive group, with an overlapping between them as individuals and professionals that is traceable during all the topics, including their consideration of the utility of the group intervention. Related to this, they seem to highly appreciate the composition of the group by only colleagues, as an important element for their self-disclosure. However, they mentioned several prejudices they had around the online groups and the heterogenetic composition of the group with both young and old colleagues. Interestingly, it seems that the most skeptical participants were the ones who knew better the group as an instrument and the intervention process.

Students and trainees share a similar trend with psychotherapists, with a tendency to search for tools to help them in their profession and a similar amount of the first person pronoun. However, while psychotherapists seem to use it as a result of their focus on their own experiences with a detached position from others, they were more able to create a cohesive group. Trainees and students focused more on the utility of the group intervention, although they had low expectations on it, highlighting how getting in touch with their emotions and limits related to the COVID situation influenced their vision of the profession of the psychologist, with a less grandiose and more realistic approach. As stated above, these conclusions should be taken with caution given the limited number of subjects on which they are based

Finally, the community group talked more about their elaboration of the pandemic experience and underlined the importance of creating connections with other people and belonging to a group. This seems confirmed by their higher use of the first person plural and cognitive words related to discrepancy and possibility. Thanks to the group, they learned to focus on the here-and-now and to tolerate their difficulty in understanding their feelings.

\section{Clinical suggestions}

Some clinical speculation traceable in this study, nevertheless its limits, could represent a suggestion for future interventions. Firstly, the focus group appears for all the participants an effective tool to capture their needs and to help them to face the situation, confirming the group as a powerful instrument during the COVID pandemic and that should be the first approach to use in emergencies. Participants' satisfaction and their request for more time or sessions as expressed in the group confirmed this positive impact.

The experience of trainees and students was particularly positive as they underlined how a defined and struc- 
tured setting was useful for them to face the uncertainty of the external environment. Taken together this points out the importance of thinking and creating devices that are adequate in terms of time for the objectives that are proposed.

Additionally, it is interesting to note the role played by the group composition. As expected, being social (online) proved to be particularly important in a time of social distancing for psychological and emotional well-being (Yalom \& Leszcz, 2005; Marmarosh et al., 2020). This was true especially for psychotherapists, where the homogeneity of the group leads participants (that did not receive any suggestion in this sense) to talk about something that they can share at that (professional) level they converged. Data that emerged from this study provide important information on their management of the current distressing situation, especially because of their role as care providers (vicarious traumatization; Aafjes-van Doorn et al., 2020), with a detachment from other people, from emotions and introspection, together with a strong overlapping between personal and professional identity (often used as a shelter). These aspects should be taken into consideration in the development of supportive interventions for psychotherapists.

\section{Limitations}

The results of this study are preliminary, and additional research is necessary to provide information about the experience of psychotherapists, students and trainees, and community people during COVID pandemic. Indeed, some limitations of this study warrant consideration.

Firstly, the size and the composition of the sample that is not representative of the Italian general population and not balanced for gender and age, with a higher percentage of females. Future studies should investigate gender differences, use larger samples, and provide more detailed demographic information.

Secondly, the use of a single measure as the LIWC. This instrument only counts and classifies words, which may be legitimately criticized as oversimplifying the full richness of the psychological phenomena that may occur when people communicate (Shaw et al., 2008). Future studies should provide information coming from multiple instruments to avoid the risk to misinterpret results. Moreover, the length of the focus groups (one session of 90 minutes) could represent a further limit due to insufficient time to develop the proposed themes. Regarding this, the number of participants in the psychotherapist's groups was higher than the others, and this might impact the distribution of the time. Similarly, the order of the topics presented by the conductors during the focus groups might influence the time dedicated to each section. Future studies should alter the order of the themes to provide a more precise understanding of this phenomenon.

Moreover, the fact that the provider of the intervention was a school of psychotherapy may represent a bias for the expectations of participants belonging to the psychology field, so additional studies are necessary to explore this difference among groups.

Finally, another limitation is also related to the need for more information about those participants who did the intervention but did not accept the invitation for the focus group. In our sample, only 52 out of 131 accepted to participate in the study. Regarding this, some hypotheses may be formulated, including the small timeframe between the invitation and the day of the focus group of only 5 days; additionally, in the recruitment, the School who provided the intervention declared that the aim of the focus group was for research. Those variables might have selected the participants, so more studies are needed to be sure that, for example, only the most satisfied individuals accept to participate in the research.

\section{References}

Aafjes-van Doorn, K., Békés, V., Prout, T. A., \& Hoffman, L. (2020). Psychotherapists' vicarious traumatization during the COVID-19 pandemic. Psychological Trauma: Theory, Research, Practice, and Policy. 12 (S1), S148-S150. doi: http://dx.doi.org/10.1037/tra0000868

Abdo, M. S., Alghonaim, A. S., \& Essam, B. A. (2020). Public perception of COVID-19's global health crisis on Twitter until 14 weeks after the outbreak. Digital Scholarship in the Humanities, fqaa037. doi: https://doi.org/10.1093/llc/fqaa037

Agosti, A., \& Rellini, A. (2007). The Italian liwc dictionary. Technical report, LIWC. net, Austin, TX. Available from: http://liwc.wpengine.com/

Barrett, D. (2020). Dreams about COVID-19 versus normative dreams: Trends by gender. Dreaming, 30(3), 216-221. https://doi.org/10.1037/drm0000149

Békés, V., \& Aafjes-van Doorn, K. (2020). Psychotherapists' attitudes toward online therapy during the COVID-19 pandemic. Journal of Psychotherapy Integration, 30(2), 238-247. http://dx.doi.org/10.1037/int0000214

Barkowski, S., Schwartze, D., Strauss, B., Burlingame, G. M., Barth, J., \& Rosendahl, J. (2016). Efficacy of group psychotherapy for social anxiety disorder: A meta-analysis of randomized-controlled trials. Journal of Anxiety Disorders, 39, 44-64. doi: https://doi.org/10.1016/j.janxdis.2016.02.005

Blackmore, C., Beecroft, C., Parry, G., Booth, A., Tantam, D., Chambers, E., Simpson, E., Roberts, E., \& Saxon, D (2009). A systematic review of the efficacy and clinical effectiveness of group analysis analytic/dynamic group psychotherapy. Centre for Psychological Services Research, School of Health and Related Research; University of Sheffield, UK.

Boldrini, T., Lomoriello, A. S., Del Corno, F., Lingiardi, V., \& Salcuni, S. (2020). Psychotherapy during COVID-19: How the clinical practice of Italian psychotherapists changed during the pandemic. Frontiers in Psychology, 11. doi: http://dx.doi.org/10.3389/fpsyg.2020.591170

Burlingame, G. M., \& Jensen, J. L. (2017) Small group process and outcome research highlights: a 25-year perspective. International Journal of Group Psychotherapy, 67(sup1), S194-S218. doi: 10.1080/00207284.2016.1218287

Burlingame, G., \& Krogel, J. (2005). Relative Efficacy of Indi- 
vidual versus Group Psychotherapy. International Journal of Group Psychotherapy, 55, 607-611. doi: http://dx.doi.org/10.1521/ijgp.2005.55.4.607

Carta, S. (2019). Guest editorial: the analyst as citizen in the world. Journal of Analytical Psychology, 64(2), 119-122.

Casagrande, M., Favieri, F., Tambelli, R., \& Forte, G. J. S. M. (2020). The enemy who sealed the world: Effects quarantine due to the COVID-19 on sleep quality, anxiety, and psychological distress in the Italian population. Sleep Medicine, 75, 12-20. doi: https://doi.org/10.1016/j.sleep.2020.05.011

Duan, L., \& Zhu, G. J. T. L. P. (2020). Psychological interventions for people affected by the COVID-19 epidemic. The Lancet, 7(4), 300-302. doi: https://doi.org/10.1016/S22150366(20)30073-0

Essam, B. A., \& Abdo, M. S. (2020). How do Arab tweeters perceive the COVID-19 pandemic?. Journal of Psycholinguistic Research. Advance online publication. doi: https://doi.org/10.1007/s10936-020-09715-6

Farber, B. A., Ort, D., \& Mayopoulos, G. (2020) Psychotherapists' preferences for television and movies during the early stages of the COVID-19 pandemic. Journal of Clinical Psychology, 76, 1532-1536. https://doi.org/10.1002/jclp.23005

Floyd, D. L., Prentice-Dunn, S., \& Rogers, R. W. (2000). A meta-analysis of research on protection motivation theory. Journal of Applied Social Psychology, 30(2), 407-429. doi: https://doi.org/10.1111/j.1559-1816.2000.tb02323.x

Foa, E., \& Rothbaum, B. (1998). Treating the trauma of rape. New York, NY: Guilford Publications Inc.

Foa, E. B., Steketee, G., \& Rothbaum, B. O. J. B. t. (1989). Behavioral/cognitive conceptualizations of post-traumatic stress disorder. Behavior Therapy, 20(2), 155-176. doi: https://doi.org/10.1016/S0005-7894(89)80067-X

Gustafson, D. H., Hawkins, R., Pingree, S., McTavish, F., Arora, N. K., Mendenhall, J., Cella, D. F., Serlin, R. C., Apantaku, F. M., Stewart, J., Salner, A. (2001). Effect of computer support on younger women with breast cancer. Journal of General Internal Medicine, 16(1), 435-445.

Herat, M. (2020). "I feel like death on legs": COVID-19 isolation and mental health. Social Sciences \& Humanities 2(1), 100042. doi: https://doi.org/10.1016/j.ssaho.2020.100042

Hill, C. A. (1987). Affiliation motivation: people who need people... but in different ways. Journal of Personality and Social Psychology, 52(5), 1008. doi: https://doi.org/10.1037/00223514.52.5.1008

Humer, E., Pieh, C., Kuska, M., Barke, A., Doering, B. K., Gossmann, K., Trnka, R., Meier, Z., Kascakova, N., Tavel, P., \& Probst, T. (2020). Provision of psychotherapy during the COVID-19 pandemic among Czech, German and Slovak psychotherapists. International Journal of Environmental Research and Public Health, 17(13), 4811. doi: https://doi.org/10.3390/ijerph17134811

Humer, E., Stippl, P., Pieh, C., Pryss, R., \& Probst, T. (2020) Psychodynamic, humanistic, systemic, and behavioral psychotherapists' experiences with remote psychotherapy during COVID-19 in Austria: A cross-sectional online survey. Journal of Medical Internet Research, 22(11), e20246. doi: https://doi.org/10.2196/20246

Jensen, H. H., Mortensen, E. L., \& Lotz, M. (2010). Effectiveness of short-term psychodynamic group therapy in a public outpatient psychotherapy unit. Nordic Journal of Psychiatry, 64(2), 106-114. doi: https://doi.org/10.3109/08039480 903443874

Kent, K. M., Hogan, M. L., Riddle, D. B., \& Heesacker, M.
(2020). Tending the grapevine: a qualitative analysis of responses to a psychotherapist-in-training testing positive for COVID-19. Counselling Psychology Quarterly, 1-26. doi: https://doi.org/10.1080/09515070.2020.1772724

King, V. L., Brooner, R. K., Peirce, J. M., Kolodner, K., \& Kidorf, M. S. (2014). A randomized trial of Web-based videoconferencing for substance abuse counseling. Journal of Substance Abuse Treatment, 46(1), 36-42. doi: https://doi. org/10.1016/j.jsat.2013.08.009

Krueger, R. A. (2014). Focus groups: A practical guide for applied research. Newbury Park, CA: Sage publications.

Lau, M., \& Kristensen, E. (2007). Outcome of systemic and analytic group psychotherapy for adult women with history of intrafamilial childhood sexual abuse. Acta Psychiatrica Scandinavica, 116, 96-104. doi: https://doi.org/10.1111/j. 1600-0447.2006.00977.x

Li, S., Wang, Y., Xue, J., Zhao, N., \& Zhu, T. (2020) The impact of COVID-19 epidemic declaration on psychological consequences: a study on active weibo users. Internaitional Journal of Environment Research and Public Health, 17(6), 2032. doi: https://doi.org/10.3390/ijerph17062032

Lima, C. K. T., de Medeiros Carvalho, P. M., Lima, I. d. A. S., de Oliveira Nunes, J. V. A., Saraiva, J. S., de Souza, R. I., Silva, C. G. L., Neto, M. L. R. J. P. R. (2020). The emotional impact of Coronavirus 2019-nCoV (new Coronavirus disease). Psychiatry Research, 112915. Advance online publication. doi: https://doi.org/10.1016/j.psychres.2020.112915

Lorentzen, S., Fjeldstad, A., Ruud, T., Marble, A., Klungsøyr, O., Ulberg, R., \& Høglend, P. A. (2015). The effectiveness of short- and long-term psychodynamic group psychotherapy on self-concept: three years follow-up of a randomized clinical trial. International Journal of Group Psychotherapy, 65(3), 362-385. doi: https://doi.org/10.1521/ijgp.2015.65.3.362

MacMullin, K., Jerry, P., \& Cook, K. (2020). Psychotherapist experiences with telepsychotherapy: pre COVID-19 lessons for a post COVID-19 world. Journal of Psychotherapy Integration, 30(2), 248-264. doi: http://dx.doi.org/10.1037/ int0000213

Marazziti, D., Pozza, A., Di Giuseppe, M., \& Conversano, C. J. P. T. T. (2020). The psychosocial impact of COVID-19 pandemic in Italy: A lesson for mental health prevention in the first severely hit European country. Psychological Trauma: Theory, Research, Practice, and Policy, 12(5), 531. doi: http://dx.doi.org/10.1037/tra0000687

Marmarosh, C. L., Forsyth, D. R., Strauss, B., \& Burlingame, G. M. (2020). The psychology of the COVID-19 pandemic: A group-level perspective. Group Dynamics: Theory, Research, and Practice, 24(3), 122. doi: http://dx.doi.org/ 10.1037/gdn0000142

Mazza, C., Ricci, E., Biondi, S., Colasanti, M., Ferracuti, S., Napoli, C., \& Roma, P. (2020). A nationwide survey of psychological distress among italian people during the COVID19 pandemic: Immediate psychological responses and associated factors. International Journal of Environmental Research and Public Health, 17(9), 3165. doi: http://dx.doi.org/10.3390/ijerph17093165

McBeath, A. G., du Plock, S., \& Bager Charleson, S. (2020) The challenges and experiences of psychotherapists working remotely during the coronavirus pandemic. Couns Psychother Res., 20, 394-405. doi: https://doi.org/10.1002/capr.12326

Moccia, L., Janiri, D., Pepe, M., Dattoli, L., Molinaro, M., De Martin, V., Chieffo, D., Janiri, L., Fiorillo, A., Sani, G., \& Di Nicola, M. (2020). Affective temperament, attachment 
style, and the psychological impact of the COVID-19 outbreak: an early report on the Italian general population. Brain, Behavior, and Immunity. Advance online publication. doi: https://doi.org/10.1016/j.bbi.2020.04.048

Pennebaker, J. W., Boyd, R. L., Jordan, K., \& Blackburn, K. (2015). The development and psychometric properties of LIWC2015. Mahwah, NJ: Lawrence Erlbaum Associates.

Pennebaker J.W., Francis M.F., \& Booth R.J. (2007). Linguistic Inquiry and Word Count (LIWC): LIWC2007. Mahwah, NJ: Lawrence Erlbaum Associates.

Pennebaker, J. M. M., \& Niederhoffer, K. (2003). Psychological aspects of naturallanguage use: Our words, our selves. Annual Review of Psychology, 54, 547-577. doi: https://doi.org/10.1146/annurev.psych.54.101601.145041.

Poletti, B., Tagini, S., Brugnera, A., Parolin, L., Pievani, L., Ferrucci, R., Compare, A. \& Silani, V. (2020). Telepsychotherapy: a leaflet for psychotherapists in the age of COVID-19. A review of the evidence. Counselling Psychology Quarterly. Advance online publication. doi: https://doi.org/ 10.1080/09515070.2020.1769557

Probst, T., Humer, E., Stippl, P., \& Pieh, C. (2020). Being a psychotherapist in times of the novel coronavirus disease: stress-level, job anxiety, and fear of coronavirus disease infection in more than 1,500 psychotherapists in Austria. Frontiers in Psychology, 11, 559100. doi: https://doi.org/ 10.3389/fpsyg.2020.559100

Probst, T., Kuska, M., Stippl, P., Pieh, C. (2020). Psychotherapists register impacts of the COVID-19 lockdown on their patients. Advance online publication. doi: http://dx.doi.org/ 10.2139/ssrn. 3581015

Rodgers, S. \& Chen, Q. (2005). Internet community group participation: Psychosocial benefits for women with breast cancer. Journal of Computer-Mediated Communication, 10(4). doi: http://dx.doi.org/10.1111/j.1083-6101.2005.tb00268.x

Rossi, R., Socci, V., Talevi, D., Mensi, S., Niolu, C., Pacitti, F., Di MArco, A., Rossi, A., Siracusano, A. \& Di Lorenzo, G. (2020). COVID-19 pandemic and lockdown measures impact on mental health among the general population in Italy.
Frontiers in Psychiatry, 11. Advance online publication. doi: https://doi.org/10.3389/fpsyt.2020.00790

Segal, S. P., Silverman, C., \& Temkin, T. (1993). Empowerment and self-help agency practice for people with mental disabilities. Social Work, 38(6), 705.

Shaw, B. R., Jeong Yeob Han, Hawkins, R. P., McTavish, F. M., \& Gustafson, D. H. (2008). Communicating about self and others within an online support group for women with breast cancer and subsequent outcomes. Journal of health psychology, 13(7), 930-939. https://doi.org/10.1177/135910530809 5067

Su, Y., Xue, J., Liu, X., Wu, P., Chen, J., Chen, C., Liu, T., Gong, W., \& Zhu, T. (2020). Examining the impact of COVID-19 lockdown in Wuhan and Lombardy: a psycholinguistic analysis on Weibo and Twitter. International Journal of Environmental Research and Public Health, 17(12), 4552. doi: https://doi.org/ 10.3390/ijerph17124552

Tausczik, Y. R., \& Pennebaker, J. W. (2010). The psychological meaning of words: LIWC and computerized text analysis methods. Journal of Language and Social Psychology, 29(1), 24-54. doi: https://doi.org/10.1177/0261927X09351676

Wallace, C. L., Wladkowski, S. P., Gibson, A., \& White, P. (2020). Grief during the COVID-19 pandemic: Considerations for palliative care providers. Journal of Pain and Symptom Management, 60, e70-e76. doi: https://doi.org/10.1016/j.jpainsymman.2020.04.012

Weinberg, H. (2020). Online group psychotherapy: Challenges and possibilities during COVID-19 - A practice review. Group Dynamics: Theory, Research, and Practice, 24(3), 201-211. doi: http://dx.doi.org/10.1037/gdn0000140

Winzelberg, A. J., Classen, C., Alpers, G. W., Roberts, H., Koopman, C., Adams, R. E., Ernst, H., Dev, P., \& Taylor, C. B. (2003). Evaluation of an internet support group for women with primary breast cancer. Cancer, 97(1), 1164-1173. doi: https://doi.org/10.1002/cncr.11174

Yalom, I. D. \& Leszcz, M. (2005). The Theory and Practice of Group Psychotherapy. New York: Basic Books. 